Skidmore College

Creative Matter

Sociology Senior Seminar Papers

Sociology

$5-2019$

\title{
Social Media Usage and its Effect on Quality of Adolescent Social Relationships
}

\section{Sadie Saltzman}

Skidmore College, ssaltzma@skidmore.edu

Follow this and additional works at: https://creativematter.skidmore.edu/socio_stu_stu_schol

Part of the Communication Technology and New Media Commons, Social Media Commons, and the Sociology Commons

\section{Recommended Citation}

Saltzman, Sadie, "Social Media Usage and its Effect on Quality of Adolescent Social Relationships" (2019). Sociology Senior Seminar Papers. 26.

https://creativematter.skidmore.edu/socio_stu_stu_schol/26

This Thesis is brought to you for free and open access by the Sociology at Creative Matter. It has been accepted for inclusion in Sociology Senior Seminar Papers by an authorized administrator of Creative Matter. For more information, please contact dseiler@skidmore.edu. 
Running Head = SOCIAL MEDIA USAGE

\title{
Social Media Usage and its Effect on Quality of Adolescent Social Relationships*
}

\author{
Sadie Mae Saltzman \\ Skidmore College
}

Word count $=6542$

*Please direct all correspondence to: Sadie Mae Saltzman, 815 North Broadway, Saratoga Springs, NY or ssaltzma@skidmore.edu. This research project was conducted with the help of Professor Andrew Lindner and Professor Catherine Berheide, along with colleagues in the Sociology Senior Seminar class. 


\section{SOCIAL MEDIA USAGE}

Social Media Usage and its Effect on Quality of Adolescent Social Relationships ABSTRACT

Does the number of social media platforms that an adolescent uses have an effect on the quality of their social relationships? As social media continues to grow and evolve, sociologists have begun to explore its effect on an individual's everyday life. I propose that the more social media platforms that an adolescent uses, the more they will experience negative effects on their social relationships. Using survey data from 786 respondents living in the United States, ages 13 to 17 and collected by the Pew Research Center in 2014 and 2015, regression analyses were conducted to determine the relationship between social media usage and its effect on quality of adolescent social relationships, controlling for sex and age. The bivariate results show a statistically significant, positive but weak association between number of social media platforms used and the social relationship experience scale. In the multivariate results, this association was still statistically significant. Additionally, the multivariate results show that the control variables, sex and age, have no significant effect on one's social relationship experience. Therefore, these results show that the more social media platforms used, the more negative a social relationship experience an adolescent will have. The results support the hypothesis and indicate that adolescents who interact with a higher number of social media platforms will experience an increased negative effect on their social relationships. In future studies, researchers should investigate how specific social media platforms influence social relationships. Additionally, this type of research should not only continue, but should refine its methods as social media continues to quickly grow and evolve. 


\section{SOCIAL MEDIA USAGE}

\section{Social Media Usage and its Effect on Quality of Adolescent Social Relationships}

According to research done by Pew Research Center in 2015, 94\% of teens who go online using a mobile device, do so daily. Additionally, $71 \%$ of adolescents are using one or more social media platforms (Pew Research Center 2015). Due to this rapid upsurge in social media usage, sociologists have become increasingly interested in the effects that social media has on individuals within society. Prior to the invention of social media, scholars explored broader themes such as internet use or time spent looking at a screen. Now, with the relatively recent creation of social media, individuals have become increasingly obsessed with their 'online image.' Additionally, social media has begun to play a big role in the development of adolescent social relationships, radically changing the manner in which they develop and evolve. Due to this lack of certainty about the influence social media has or does not have on adolescent relationships, scholars are enthusiastically looking for opportunities to investigate how the new media are affecting adolescents' lives.

Because of its recent invention, research of social media and the quality of effects they have on individuals is only in the beginning stages. Guided by insights from social development theories, studies have proposed that social media does have a range of effects on the development of social relationships (Blais et al. 2007; Bargh et al. 2002; Baym et al. 2007; Abar et al. 2018; Gennaro and Dutton 2007; Brignall and Valey 2005; McKenna et al. 2002; Waskul and Douglass 1997; Gianesini and Brighi 2015). Some scholars propose that the internet has some degree of positive influence on the development of social relationships (Blais et al. 2007; Bargh et al. 2002; Baym et al. 2007; Abar et al. 2018; McKenna et al. 2002). Alternatively, other scholars propose that the internet has little influence or negative influence on the development of 


\section{SOCIAL MEDIA USAGE}

social relationships (Brignall and Valey 2005; Gennaro and Dutton 2007; Waskul and Douglass 1997; Gianesini and Brighi 2015). Considering these studies, it is logical to explore whether an adolescents' social relationships are being positively or negatively influenced by the use of social media. Adolescents are an important age group to look at in terms of this research because they are still developing socially and emotionally. Additionally, adolescents are frequent users of social media. This type of research would explain how social media alters an adolescents experience within their social environment. Because the invention of social media is still relatively new, it is important to gain a deeper understanding of the effects it has on individuals within society, especially if it is found to emit negative impacts. Results will shed light on whether social media usage helps or hinders the development of social relationships among adolescents.

Adding on to previous studies regarding social media and social relationships, this analysis will attempt to answer the question, does the number of social media platforms an adolescent uses have an effect on the quality of their social relationships? I hypothesize that the more social media platforms an adolescent uses, the more they will experience negative effects on their social relationships.

\section{THEORETICAL FRAMEWORK}

Erving Goffman's dramaturgical theory provides a compelling connection to the usage of social media. Goffman comments on the self and how one's personality, or outside image, is perceived by the self and others. Within this theory, he argues that every aspect of one's self is a performance. The effect social media has on one's individual self has similarities to Goffman's dramaturgical theory. 


\section{SOCIAL MEDIA USAGE}

Goffman (1959) uses the metaphor of a play to describe his theory and argues that people are always acting and can never be their true selves. More specifically, Goffman (1959) attributes every action an individual takes to be some type of performance that occurs within a particular setting with specific actors involved. Goffman (1959) writes, "In a sense, and in so far as this mask represents the conception we have formed of ourselves-the role we are striving to live up to-this mask is our truer self, the self we would like to be" (19). He then goes on to say that the formation we create of ourselves eventually embodies the essential components of our personality (Goffman 1959).

In this theory, Goffman introduces terms such as face and impression management, which indicate that one must keep up with and maintain their performed self. For example, "the term face may be defined as the positive social value a person effectively claims for himself by the line others assume he has taken during a particular contact" (Goffman 1967: 5). In other words, Goffman (1967) speculates that once someone describes a positive self-image of him or herself to others, there is a sense of pressure that individual now possesses in order to maintain and live up to that positive image. Along with the concept of face, Goffman (1959) introduces a new term called impression management. Impression management is a process, conscious or subconscious, where what is conveyed to others about a specific person is chosen by that person in order to make a good impression (Goffman 1959). The possibility of inconsistency in how one expresses him or herself can lead to some degree of humiliation and of being discredited (Goffman 1967). In terms of Goffman's theory, Cahill (1998) argues "that although Goffman was clearly thinking only of face-to-face interactions, his description is useful as a starting point for describing an intact social bond, regardless of whether the participants are co-present or not" (Brignall and Valey 2005: 339). 


\section{SOCIAL MEDIA USAGE}

The similarities between Goffman's dramaturgical theory and the effect social media has on the perception of self are clear. Social media can be considered a performance. An individual chooses and develops all aspects of their online self. For example, one can select exactly what they want to post in order to convey a certain identity to their audience. This is a form of impression management. One will post what they think will make them look the best to their audience or that will convey a certain attitude or message. In line with Goffman's argument, social media is an added layer of performance on top of the self, which is an already a fabricated performance.

Building off of Goffman's theory, an increased use of social media platforms indicates that individuals must perform additional personas. Each social media platform used, can be thought of as a separate persona that an individual must maintain. A multitude of personas becomes difficult to manage. Therefore, I intend to explore how use of social media platforms among adolescents impacts their social relationships. Consequently, I hypothesize that the more social media platforms an adolescent uses, the more they will experience negative effects on their social relationships.

\section{LITERATURE REVIEW}

Works that focus on the range of effects social media usage may have on individuals creates a dialogue between themes of social relationships, social capital, and mental health. Additionally, studies surrounding media consumption as a whole, serve as a solid background for social media research. In this section, major themes, like those previously mentioned, surrounding past research done on social media will be explored. 


\section{SOCIAL MEDIA USAGE}

\section{Media}

Before there was research conducted on the various effects social media have on individuals, research was done on media consumption as a whole. This literature included comments on the ways film, television, the internet, and other forms of media influence society (Deuze 2011; Kubitschko and Knapp 2012).

To begin, Mark Deuze (2011) explains the implication media have had on individuals in society. He explains that media are increasingly becoming invisible to the point where "people in general do not even register the presence of media in their lives" (Deuze 2011: 143). This quality of media has led to extensive social and cultural repercussions (Deuze 2011). Additionally, he explains that as media becomes increasingly invisible, our experience of reality becomes modified (Deuze 2011). This invisible quality media possesses becomes even more prominent with social media. Social media promotes the synergy of "offline life" and "online life."

However, not all scholars agree with Deuze (2011). Kubitschko and Knapp (2012) comment on Deuze's (2011) theory regarding increasing invisibility among media within an individual's life. They explain that Deuze's (2011) argument, in terms of invisibility, comes off as though media have disappeared entirely (Kubitschko and Knapp 2012). Rather, Deuze (2011) meant that individuals lose the cognitive ability to perceive media through visual means (Kubitschko and Knapp 2012). However, it is important to keep in mind that Deuze (2011) began the conversation regarding the visibility of media in everyday life, regardless of whether or not he clearly defined invisibility. Without Deuze's (2011) article, Kubitschko and Knapp (2012) would have nothing to critique or add on to. Therefore, although Deuze's (2011) argument lacks some clarity, it instigates the consideration of media as becoming increasingly 


\section{SOCIAL MEDIA USAGE}

invisible within our day to day lives. When considering the topic of this research, it is important to contemplate the increasing invisibility of social media and how that has an impact on its users.

These studies on media are an important basis for the rest of the literature discussed.

Regardless of the criticism, both articles were written while social media was still in its beginning stages. Therefore, these studies provide a premature speculation on the potential for the impact social media has on individuals. Literature explicitly discussing social media's effects follows.

\section{Social Relationships}

The literature regarding the development of social relationships is continuously growing. Scholars have proposed that media and internet use have had an effect on the development of social relationships (Blais et al. 2007; Bargh et al. 2002; Baym et al. 2007; Abar et al. 2018; Gennaro and Dutton 2007; Brignall and Valey 2005; McKenna et al. 2002; Waskul and Douglass 1997; Gianesini and Brighi 2015). Some scholars propose that the internet has some degree of positive influence on the development of social relationships (Blais et al. 2007; Bargh et al. 2002; Baym et al. 2007; Abar et al. 2018; McKenna et al. 2002). In regard to relationships among adolescents and their parents, Abar et al. (2018) found in their study that youth who were connected with their parents on Facebook were less likely to use marijuana or drink alcohol in high school. This study suggests that an adolescent's interaction with a parent over social media has an effect on their social relationships within a high school social hierarchy (Abar et al. 2018).

In terms of social relationships among adolescent friendships, some assume that friendships created on the internet are less legitimate than those formed in person. However, in more recent years, "research is beginning to support the stimulation hypothesis, which proposes that using internet-based communication may stimulate relationship formation with strangers 


\section{SOCIAL MEDIA USAGE}

(McKenna et al. 2002) and also improve the quality or closeness of relationships with knownothers" (Blais et al. 2007: 524). Due to the unique structure of the internet, users are able to connect to others with similar interests (McKenna et al. 2002). According to Blais et al., (2007) "in addition to receiving emotional support, adolescents are able to experiment with identities and social strategies within their close relationships" (523). Bargh et al. (2002) suggest two features unique to the internet that lead an individual to express their true self. These features include the anonymity made possible on the internet and the lower risk that comes when disclosing possibly negative aspects of oneself on the internet as opposed to in a face-to-face interaction (Bargh et al. 2002). Due to the distinctive structure the internet possesses, individuals are able to tap into close relationships that they may not have had the chance to experience without the internet (Blais et al. 2007; McKenna et al. 2002; Bargh et al. 2002).

Alternatively, other scholars propose that the internet has little influence or negative influence on the development of social relationships (Brignall and Valey 2005; Gennaro and Dutton 2007; Waskul and Douglass 1997; Gianesini and Brighi 2015). Waskul and Douglass (1997) suggest that the internet brings about poor qualities in social relationships such as "anonymity, lack of role strain, multiple projected images of oneself, multiple front stages, the lack of a collective social contract, the ability to play multiple social roles, and the lack of necessity to deal with individuals or groups with which one does not agree" (Brignall and Valey 2005: 343). Brignall and Valey (2005) consider that "even if the students are interacting with fellow classmates while online, is it not reasonable that the use of a computer in mediating those interactions will alter the interaction rituals in which they engage?" (344). Can friendships that are made face-to-face and friendships that are made over the internet be classified as the same type of relationship? Gennaro and Dutton (2007) conclude that "online friendships are not driven 


\section{SOCIAL MEDIA USAGE}

by any mechanistic social or technological determinism" (615) but rather "by one's experience as a user" (615). Additionally, Gennaro and Dutton (2007) suggest "the rise of online social networking application such as Facebook, Flickr, Friendster, MySpace, and YouTube, which allow users to come into contact and interact with many other users, are likely to further reinforce the role of internet usage patterns on the development of social networks" (615). These scholars have all suggested that relationships made online are inherently different than relationships made face-to-face. The potential explanation as to why scholars find different results may be the product of different measures or different samples. Additionally, the year in which the research was done may have a large impact on the research results, especially considering the constantly changing nature of the online environment. There is still research needed to determine if social media usage has a positive or negative effect on social relationships. As the internet has become a central environment for human connection, this research is more necessary than ever.

\section{Social Capital}

Some scholars have committed their research to the study of social media and its contribution to an individual's social capital (Ridder and Bauwel 2013; Quinn 2016; Marwick and boyd 2014; Bohn et al. 2014). Sociologist Nan Lin (1999) clearly defines the notion of social capital as, "investment in social relations with expected returns" (30). It is important to consider the impact social media use can have on one's social capital. When considering social media as a method of receiving social capital, one could consider the act of posting on social media as an investment in social capital. Individuals post on social media in order to receive some type of reaction which in turn gives them some degree of social capital (Ridder and Bauwel 2013; Quinn 2016; Bohn et al. 2014). Additionally, it is important to consider that self-objectification begins 


\section{SOCIAL MEDIA USAGE}

as early as elementary school among female adolescents (Lindberg et al. 2006). Therefore, the push to self-objectify may be caused by this need to gain social capital.

The contribution to an individual's social capital can have a range of effects on one's social relationships. Some scholars have concluded that whether usage of social media impacts subjective well-being negatively or positively depends on how one uses them (Verduyn et al. 2017). Bohn et al. (2014) found that an increase usage of Facebook led to an increase of social capital. Verduyn et al. (2017) found that, "social network sites have the potential to increase our subjective well-being by allowing us to increase our social capital and feeling of connectedness due to active usage of these sites" (295-296). They go on to explain that although social networking sites can evoke feelings of connectedness, they can also cause feelings of distress (Verduyn et al. 2017). Specifically, social networks have the potential to "elicit social comparisons and envy due to passive usage of these sites" (Verduyn et al. 2017: 296). When individuals experience distress due to feelings of competition between users, social media has been found to increase drama in one's life (Bohn et al. 2014; Marwick and boyd 2014). Specifically, Marwick and boyd (2014) discuss that social media has changed how conflict among adolescents operates. For example, they say that "the persistence and involvement of audiences in environments like Facebook engender a performative, participatory model of youth aggression. Therefore, while an increase in social capital via the internet can lead to an increase of positive effects on one's social relationships, it can also lead to an increase of negative effects.

\section{Mental Health}

Continuing with the notion that social media can cause distress in one's life, it is important to consider to what extent social media can impact an individual's mental health. 


\section{SOCIAL MEDIA USAGE}

Some scholars commit their work to trying to understand if there is a link between social media and mental health (Pitts 2012; Verduyn et al. 2017; Fardouly et al. 2018).

As previously discussed, Verduyn et al. (2017) concluded that whether or not social media contributes to one's subjective well-being depends on how users consume and interact with social media. Along similar lines, Pitts' (2012) found that there is a link between the appearance of symptoms of depression and media usage. Pitts (2012) suggests that "perhaps the prevalence of depression among the younger population is a result of overstimulation to media in our culture and turning all our media devices off, and tuning out of cultural media messages from time to time would help reduce frequency of depressive symptoms experienced by adolescents" (250). On the other hand, Fardouly et al. (2018) investigate the effect parental control can have on an adolescent's use of social media. This control over social media by parents is thought to decrease symptoms of poor mental health Fardouly et al. (2018). For example, they found that "greater parental control over the time preadolescents spend on social media was associated with better preadolescent mental health (depressive symptoms, appearance satisfaction, life satisfaction)" (Fardouly et al. 2018: 1465). In terms of this study, experiencing poor mental health because of social media usage would be classified as a negative experience. Exhibiting poor mental health would lead to more difficulties for adolescents attempting to form social relationships. This literature suggests that social media can have an impact on both subjective well-being and mental health.

Although this type of research on social media is still relatively new, there are already formed views on whether an increased usage of the internet and social media lead to more positive or to more negative effects on one's social relationships. Within the topics of social relationships, social capital, and mental health that were explored above, scholars have found 


\section{SOCIAL MEDIA USAGE}

results that support either side of the dispute. There is no strong indication amongst the literature that shows definitely that the internet and social media lead to either a more positive or a more negative effect on one's social relationships. Because of this inconsistency amongst past literature, this study is necessary in order to continue to contribute to the literature surrounding social media usage.

\section{METHODS}

To investigate the effect social media use has on an adolescents' social relationships, this research project analyzes survey data from the Pew Research Center. Within this study, the target population consists of parents of teens ages 13 to 17 and teens aged 13 to 17 years old living in the United States. The sample population, of 4,111 individuals, was conducted by the GfK Group sampling households from KnowledgePanel® which is an online database meant to be representative of the United States. Though 1,084 parents completed the surveys, 24 unpaired parents had to be removed since only 1,060 teens completed the survey. The size of the sample consists of 1,060 parents of 13 to 17 year olds and 1,060 teens aged 13 to 17 . Because the variables used in this study were only asked of the teens, this study examines 786 respondents. This survey yielded a response rate of 51.6 percent. The study conducted research from September 25 to October 9, 2014 and February 10 to March 6, 2015. The study involved twelve in-person focus groups and four online focus groups. This dataset's unit of analysis is the individual. More information on this dataset is available on the Pew Research Center website at (http://www.pewinternet.org/2015/08/06/methods-34/).

My study examines two different sets of variables: 1) variables measuring the number of social media platforms used by adolescents, and 2) variables on the quality of adolescent social relationships. To measure the independent variable of number of social media platforms one 


\section{SOCIAL MEDIA USAGE}

uses, the question asks, "which of the following social media do you use?" The question applies to the following social media platforms: Facebook, Twitter, Instagram, Snapchat, Vine and Tumblr. The original possible answers for this question are 1. Yes and 2. No. This variable has been dummied into the responses 0 . No and 1 . Yes. The missing data from this question has been removed. Then, responses to each social media platform were added up in order to determine the number of social media platforms used by an adolescent. Cronbach's alpha for this index is 0.580 , meaning there is internal consistency among the variables within the scale.

To assess my dependent variable of quality of social relationships, I use multiple variables to determine how social media has had an effect on social relationships. The questions from the dataset ask different questions regarding what the respondent feels about social media and also asks whether or not the respondent has experienced a specific situation on social media. The questions are as follows: "in general does social media make you feel worse about your own life because of what you see from other friends on social media?", "in general does social media make you feel pressure to post content that will be popular and get lots of comments or likes?", “in general does social media make you feel pressure to only post content that makes you look good to others?", "do you experience any of the following on social media? People posting about things you weren't invited to?”, “do you experience any of the following on social media? People stirring up drama?”, “do you experience any of the following on social media? People posting things about you that you can't change or control?" For the questions asked, the variables have been recoded into 0 . No 1 . Yes, a little and 2. Yes a lot. The other responses and missing data has been removed from all variables. Then, responses to each question will be added up in order to determine a score one has for quality of experience of social relationships. All of these variables will be measured on a scale from 0 , most positive experiences to 12 , most negative 


\section{SOCIAL MEDIA USAGE}

experiences, involving social media's effect on social relationships. Cronbach's alpha for this index is 0.789 , meaning there is internal consistency among the variables within the scale. Additionally, this study controls for age and sex. The sex variable was dummied as 1 . Male and 0. Female, which this study treats as a measure of gender.

\section{FINDINGS}

\section{Univariate Results}

Table 1 reports the mean, median and standard deviation for all variables. The mean for number of social media platforms used is about 3 social media platforms with a standard deviation of about 1.5. The mean for the social relationship experience scale is about 3 with a standard deviation of about 2.5. On the social relationship experience scale, this average indicates adolescents have more positive experiences than negative. The average age is around 15 years old and $47 \%$ of the sample are male.

***Table 1 about Here***

This research identifies how many social media platforms an adolescent uses in this particular dataset. Figure 1 shows that adolescents use a range of a number of platforms. Most adolescents, $23 \%$, only use one social media platform. $21 \%$ of adolescents use three social media platforms and $20 \%$ of adolescents use two social media platforms. Only $2 \%$ of adolescents use no social media platforms, indicating that the use of social media is a large part of an adolescent's lifestyle.

\footnotetext{
***Figure 1 about Here***
}

Figure 2 shows the social relationship experience scale. It reports that more adolescents have never, or have had a few, negative experiences with social media effecting their social relationships. Additionally, it is important to recognize that there are a small number of 


\section{SOCIAL MEDIA USAGE}

adolescents who have had very negative experiences from social media effecting their social relationships. While more adolescents have positive experiences, there are still some adolescents that have very negative experiences.

***Figure 2 about Here***

Figure 3 and Figure 4 both show the control variables, sex and age. Figure 3 shows that there are more females in the sample than male. In terms of age, there is a similar percentage of adolescents for each age year sampled, from 13 years of age to 17.

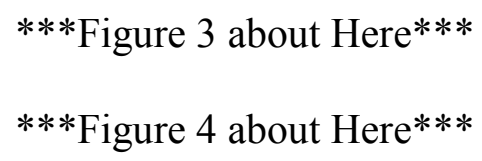

\section{Bivariate Results}

Correlation coefficients are used to calculate the bivariate relationship between dependent, independent, and control variables. Table 2 shows the correlations between social relationship experience scale, number of social media platforms used, age and sex. With a value of 0.250 , there is a positive, weak, statistically significant relationship between social relationship scale and number of social media platforms used in explaining that those who engage with more social media platforms are faced with an increase of negative social relationship experiences. Additionally, the bivariate results show a statistically significant relationship between social media platforms used and both age $(r=.177)$ and $\operatorname{sex}(r=-.240)$. Therefore, the bivariate results show that younger, male respondents use fewer social media platforms. Lastly, there is a negative, very weak, statistically significant relationship between social relationship experience scale and $\operatorname{sex}(\mathrm{r}=-.077)$. Therefore, males score more positively on the social relationship experience scale. All of these relationships are significant at the $p<.05$ level. 
SOCIAL MEDIA USAGE

***Table 2 about Here***

Multivariate Results

While controlling for age and sex in the multivariate regression, number of social media platforms used remains statistically significant (see Table 3). In the regression equation, the only significant relationship of the dependent variable is with the independent variable. The $\mathrm{R}^{2}$ shows that 25.1 percent of the variation in the social relationship experience scale can be explained by the independent variables, number of social media platforms used, age and sex. This regression model is statistically significant at the $p<.05$ level $(F=17.542)$.

***Table 3 about Here***

In terms of the unstandardized regression coefficient, for each additional social media platform used, there is a .448 increase on the social relationship experience scale, meaning the more social media platforms used, the more negative the experience within one's social relationships. The standardized regression coefficients display that number of social media platforms used has the biggest effect on the social relationship experience scale. Although age and sex were significant in the bivariate analysis, this relationship disappears in the regression due to the mediating effect that number of social media platforms used has on the social relationship experience scale. The regression supports my hypothesis that the more social media platforms an adolescent uses, the more they will experience negative effects on their social relationships.

\section{DISCUSSION}

Overall, the results show that an individual's rating on the social relationship experience scale is influenced by the number of social media platforms they use. While some studies look at social media as a conglomerate entity, this analysis focused on the impact of the number of 


\section{SOCIAL MEDIA USAGE}

distinct social media platforms. These results support my hypothesis that the more social media platforms used, the more negative experiences one will have within their social relationships. Both age and sex had no effect on the social relationship experience scale. Therefore, age and sex both do not change the quality of one's experience within their social relationships.

Some literature finds that the internet has some degree of positive influence on the development of social relationships (Blais et al. 2007; Bargh et al. 2002; Baym et al. 2007; Abar et al. 2018; McKenna et al. 2002). The result of this study does not support these ideas. In line with other literature, the internet has a negative influence on the development of social relationships (Brignall and Valey 2005; Gennaro and Dutton 2007; Waskul and Douglass 1997; Gianesini and Brighi 2015). It is important to keep in mind that this literature is focused on internet usage and not social media usage. Because social media is still relatively new, there is limited literature that focuses solely on the effects of social media. However, this research does add to the scholarly discussion about how social media usage among adolescents effects the quality of their social relationships.

The results cannot confirm Goffman's dramaturgical theory, as this research is adapted to adolescent social media usage and not face-to-face interactions. However, there are similarities between social media and Goffman's theory. Social media is in itself a performance. Individuals decide how they will portray their identity online. Along with Goffman's argument, each social media platform may mimic an additional and unique persona that an individual curates and maintains. Maintaining multiple personas becomes difficult to manage which leads to more negative of an experience within their social relationships. The multiple personas that adolescents must maintain on each individual social media platform may factor into the negative experiences they are facing. When an adolescent must juggle multiple personas, they may 


\section{SOCIAL MEDIA USAGE}

prioritize maintaining their online image over maintaining quality relationships within their social circles.

Further, adolescents utilize a combination of both public online identities and private offline identities that are shared with specific social groups. This creates a splintering sense of self identity. With a constant internal editorial mindset, adolescents who use multiple platforms and manage several identity profiles are constantly calculating what to share, who to share with and when to share, all while weighing the social implications and reactions for every post or comment. When an individual feels this type of pressure when posting content on social media, their social relationships are impacted. This research supports the notion that an increased use of social media among adolescents leads to more negative experiences within their social relationships.

\section{CONCLUSION}

This study examined the relationship between social media usage among adolescents and its effect on quality of social relationships. Using survey data from 786 respondents living in the United States, ages 13 to 17 and collected by the Pew Research Center in 2014 and 2015, regression analyses were conducted to determine the relationship between social media usage and its effect on quality of adolescent social relationships, controlling for sex and age. The regression results support my hypothesis indicating that the more social media platforms used among adolescents, the more negative the impact is on their social relationships.

These findings propose that an increased usage of social media negatively impacts adolescents' lives. Although some research has found that there are benefits to internet usage, there are differences between the internet and social media. Social media has a constant and ever-changing nature, mostly because they are easily accessed through a smartphone at anytime. 


\section{SOCIAL MEDIA USAGE}

From a technological standpoint, social media will continue to grow and evolve. Unless some action is taken encouraging a decreased use of social media among adolescents, teens will continue to experience more negativity within their social relationships.

\section{Limitations}

It is important to consider the limitations this research possesses. First, the data set from Pew Research Center did not possess any variables discussing time spent on social media. This study would have benefitted from a variable measuring the time spent on social media instead of the variable, number of social media platforms used. Although time spent on social media does have an effect on quality of social relationship experience, the time variable would be more engaging research to share with the public. Next, the data used for this research is from 2014 and 2015. Overall, this data is not particularly old. However, because the research topic is social media, this data has the potential to be outdated. Because social media is something that is constantly changing, more current data would be beneficial for this type of study. Research using data from 2018 would be more telling than the findings presented in this paper.

\section{Future Research}

Due to the nature of social media and its ongoing evolution, this type of research would greatly benefit from continuous up to date research. Findings from a study on social media will have a range of results since the technologies continue to evolve and change. Facebook, Instagram, Twitter, Snapchat, Vine, and Tumblr were all invented within the last fifteen years. There will likely be new innovations and inventions over the next fifteen years which will further impact adolescent social relationships. Additionally, it would be interesting to explore how specific social media platforms influence one's social relationship experiences. Future research 


\section{SOCIAL MEDIA USAGE}

could isolate individual social media platforms in order to see if some impact social relationships more negatively than others.

Overall, the results from this study conclude that when adolescents use multiple social media platforms they face an increased number of negative experiences in their social relationships. When adolescents use more than one social media platform, they accrue more personas that demand a type of social performance and constant maintenance. This creates emotional strain and causes distraction, leaving adolescents subject to facing increased negative experiences within their social relationships. Social media shows no sign of slowing its growth even as its negative qualities become more widely known. While the destructive impacts social media has on adolescents becomes increasingly acknowledged, and entertainment content reflects society's acceptance of this negativity as a new rite of passage for growing up, without some larger action, this trend will continue to negatively impact social relationships in future generations. 
SOCIAL MEDIA USAGE

\section{REFERENCES}

Abar, Caitlin C., Sarah Farnett, Kayla Mendola, Kaitlyn Koban, and Sharon Sarra. 2018.

"Relationships between parent-child social media interactions and health behaviors." Journal of Substance Abuse 23(3): 335-337.

Bargh, John A., Katelyn Y.A. Mckenna, and Grainne M. Fitzsimons. 2002. "Can You See the Real Me? Activation and Expression of the "True Self" on the Internet." Journal of Social Issues 58(1):33-48.

Baym, Nancy K., Adrianne Kunkel and Andrew Ledbetter. 2007. "Relational Quality and Media Use in Interpersonal Relationships." New Media \& Society 9(5):735-752.

Blais, Julie J., Wendy M. Craig, Debra Pepler, and Jennifer Connolly. 2007. “Adolescents Online: The Importance of Internet Activity Choices to Salient Relationships.” Journal of Youth and Adolescence 37(5):522-36.

Bohn, Angela, Christian Buchta, Kurt Hornik and Patrick Mair. 2014. "Making Friends and Communicating on Facebook: Implications for the Access to Social Capital." Social Networks 37:29-41.

Brignall, Thomas W., and Thomas Van Valey. 2005. "The Impact of Internet Communications on Social Interaction." Sociological Spectrum 25(3):335-348.

Cahill, Spencer E. 1998. "Toward a Sociology of the Person." Sociological Theory 16(2): 131148.

Deuze, Mark. 2011. “Media Life.” Media, Culture, \& Society 33(1):137-148.

Fardouly, Jasmine, Natasha R. Magson, Carly J. Johnco, Ella L. Oar and Ronald M. Rapee. 2018. "Parental control of the time preadolescents spend on social media: Links with 


\section{SOCIAL MEDIA USAGE}

preadolescents' social media appearance comparisons and mental health." Journal of Youth and Adolescence. 47(7): 1456-1468.

Gianesini, Giovanna and Antonella Brighi. 2015. "Cyberbullying in the Era of Digital Relationships: The Unique Role of Resilience and Emotion Regulation on Adolescents' Adjustment." Sociological Studies of Children and Youth 19:1-46.

Goffman, Erving. 1959. The Presentation of Self in Everyday Life. New York: Anchor.

Goffman, Erving. 1967. Interaction Ritual: Essays on Face to Face Behavior. New York: Pantheon Books.

Gennaro, Corinna D., and William H. Dutton. 2007. "Reconfiguring Friendships: Social Relationships and the Internet." Information, Communication \& Society 10(5):591-618.

Lin, Nan. 1999. "Building A Network Theory of Social Capital." Connections 22(1): 28-51.

Lindberg, Sara M., Janet Shibley Hyde and Nita Mary McKinley. 2006. "A measure of objectified body consciousness for preadolescent and adolescent youth." Psychology of Women Quarterly 30:65-76.

Marwick, Alice, and danah boyd. 2014. "'It's just drama': teen perspectives on conflict and aggression in a networked era." Journal of Youth Studies 17(9): 1187-1204.

Mckenna, Katelyn Y.A., Amie S. Green and Marci E.J. Gleason. 2002. "Relationship formation on the Internet: what's the big attraction?" Journal of Social Issues 58(1): 9-31.

Pew Research Center 2014-2015. "Sept. 25-Oct. 9, 2014 and Feb. 10-March 6, 2015 - Teens.”

Pitts, Kristin. 2011. “Adolescent Depression: the Effects of Media Use, Sex, and Social Resources.” International Journal of Contemporary Sociology 49(2): 239-254.

Quinn, Kelly. 2016. "Contextual Social Capital: Linking the Contexts of Social Media use to its Outcomes." Information, Communication \& Society 19(5):582-600. 


\section{SOCIAL MEDIA USAGE}

Ridder, Sander De, and Sofie Van Bauwel. 2013. "Commenting on pictures: Teens negotiating gender and sexualitites on social networking sites." Sexualities 16(5/6): 565-586.

Verduyn, Philippe, Oscar Ybarra, Maxime Rsibois, John Jonides and Ethan Kross. 2017. "Do Social Network Sites Enhance Or Undermine Subjective Well-being? A Critical Review." Social Issues \& Policy Review 11(1):274-302.

Waskul, Dennis, and Mark Douglass. 1997. "Cyberself: The Emergence of Self in Online Chat." Information Society 13(4): 375-397. 
SOCIAL MEDIA USAGE

Table 1. Means, Medians, and Standard Deviations for Variables $(\mathrm{N}=786)$

\begin{tabular}{lccc}
\hline \hline \multicolumn{1}{c}{ Variable } & Mean & Median & SD \\
\hline Number of Social Media Platforms Used & 2.83 & 3.00 & 1.530 \\
Social Relationship Experience Scale & 3.32 & 3.00 & 2.572 \\
Age & 15.11 & 15.00 & 1.421 \\
Sex & 0.47 & 0.00 & 0.499 \\
\hline
\end{tabular}


SOCIAL MEDIA USAGE

Table 2. Correlations between Social Relationship Experience Scale and Three Variables (listwise deletion, two-tailed test, $\mathrm{N}=786$ )

\begin{tabular}{|c|c|c|c|}
\hline Variable & $\begin{array}{l}\text { Number of social } \\
\text { media platforms used }\end{array}$ & Male & $\begin{array}{l}\text { Age of child } \\
\text { selected }\end{array}$ \\
\hline $\begin{array}{l}\text { Social Relationship } \\
\text { Experience Scale }\end{array}$ & $.250^{*}$ & $-.077^{*}$ & .025 \\
\hline $\begin{array}{l}\text { Number of social media } \\
\text { platforms used }\end{array}$ & & $-.240^{*}$ & $.177^{*}$ \\
\hline Male & & & 0.004 \\
\hline
\end{tabular}


SOCIAL MEDIA USAGE

Table 3. Regression of Social Relationship Experience on All Variables

\begin{tabular}{lcc}
\hline \multicolumn{1}{c}{ Variable } & $b$ & $\beta$ \\
\hline $\begin{array}{l}\text { Number of Social Media } \\
\text { Platforms Used }\end{array}$ & .448 & $.249 *$ \\
Male & -.094 & -.017 \\
Age & -.038 & -.020 \\
Constant & 2.673 & \\
$\mathrm{R}^{2}=.251 ; F(3,785)=17.542 *$ & & \\
$* p<.05$ & &
\end{tabular}


SOCIAL MEDIA USAGE

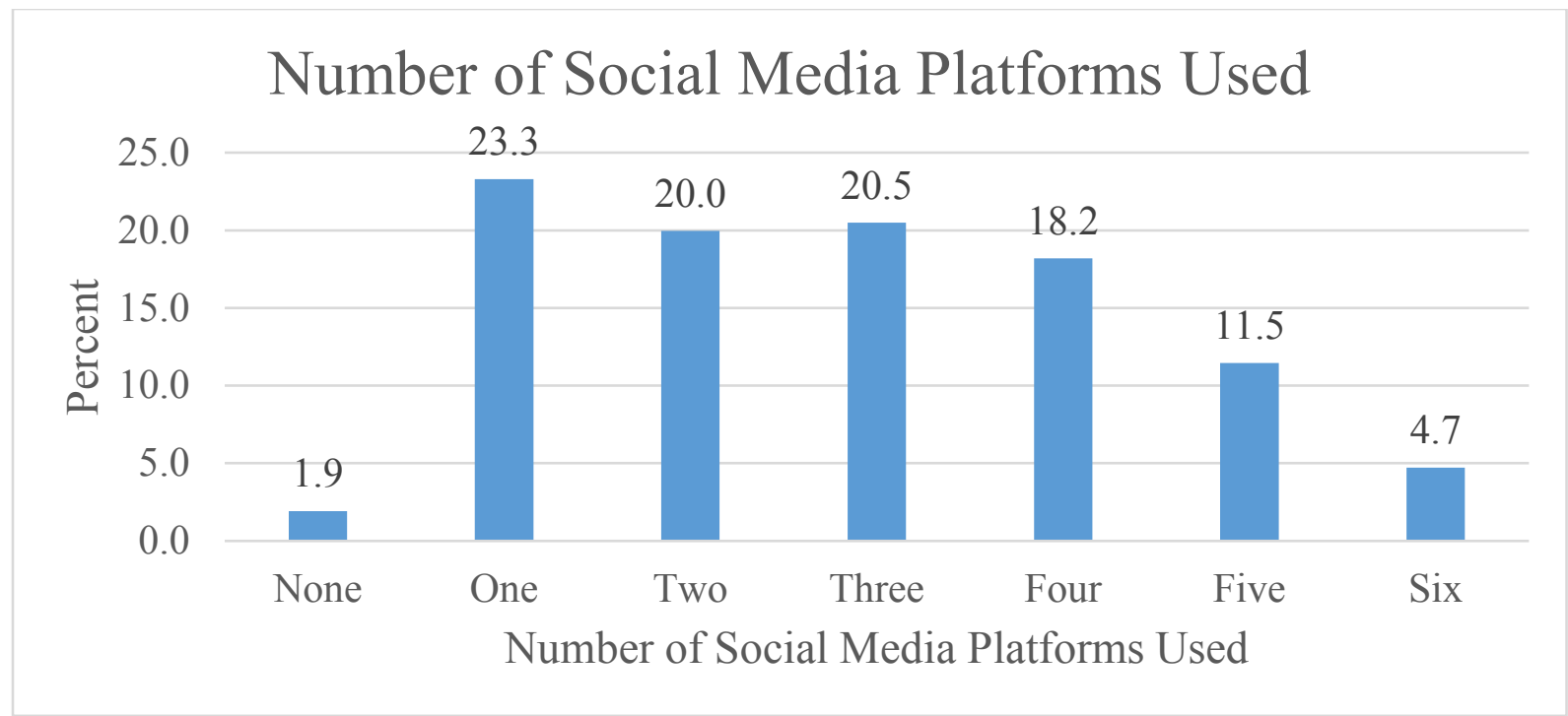

Figure 1. Number of Social Media Platforms Used in Percentages 
SOCIAL MEDIA USAGE

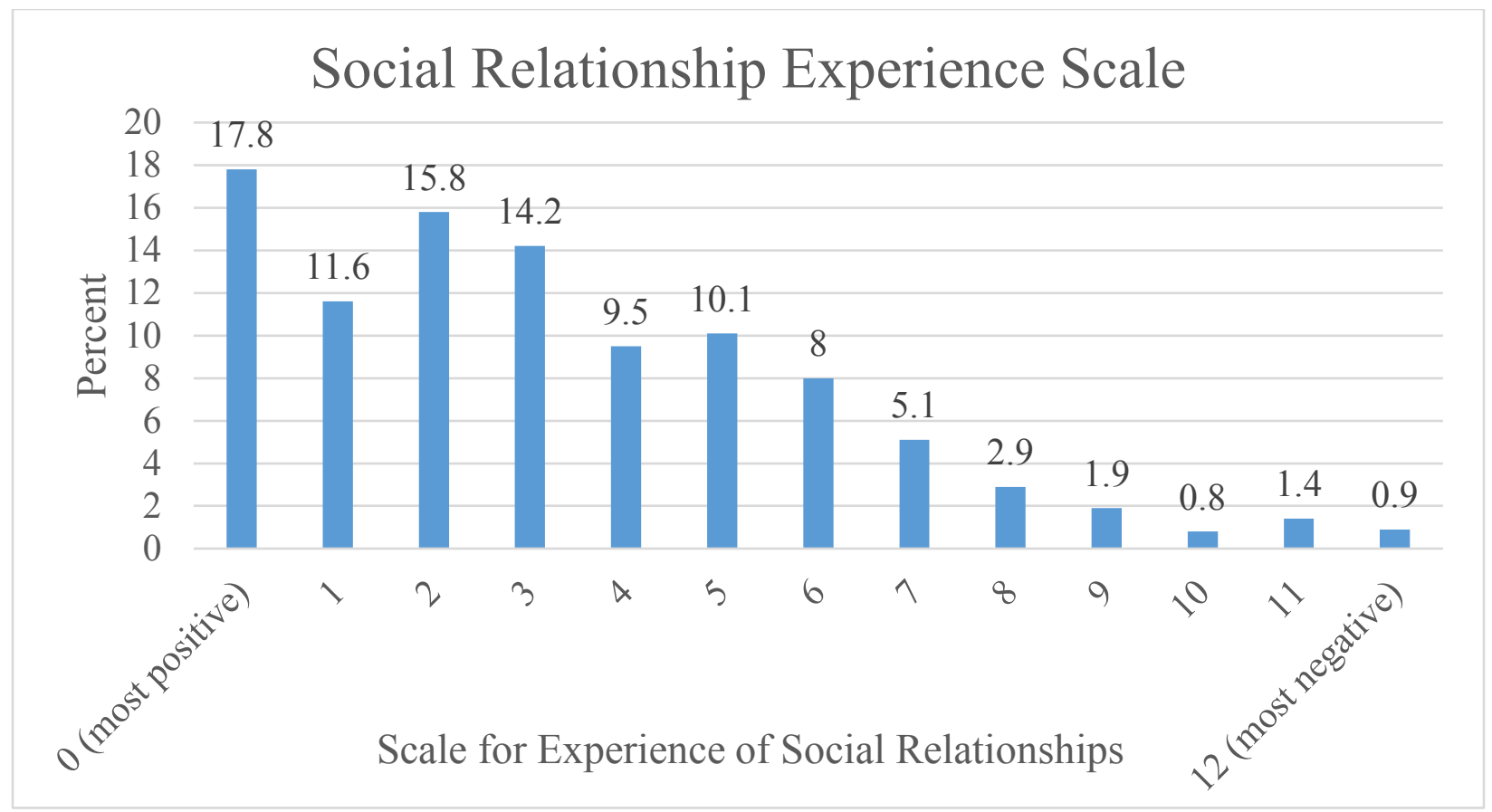

Figure 2. Scale for Experiences of Social Relationships in Percentages 
SOCIAL MEDIA USAGE

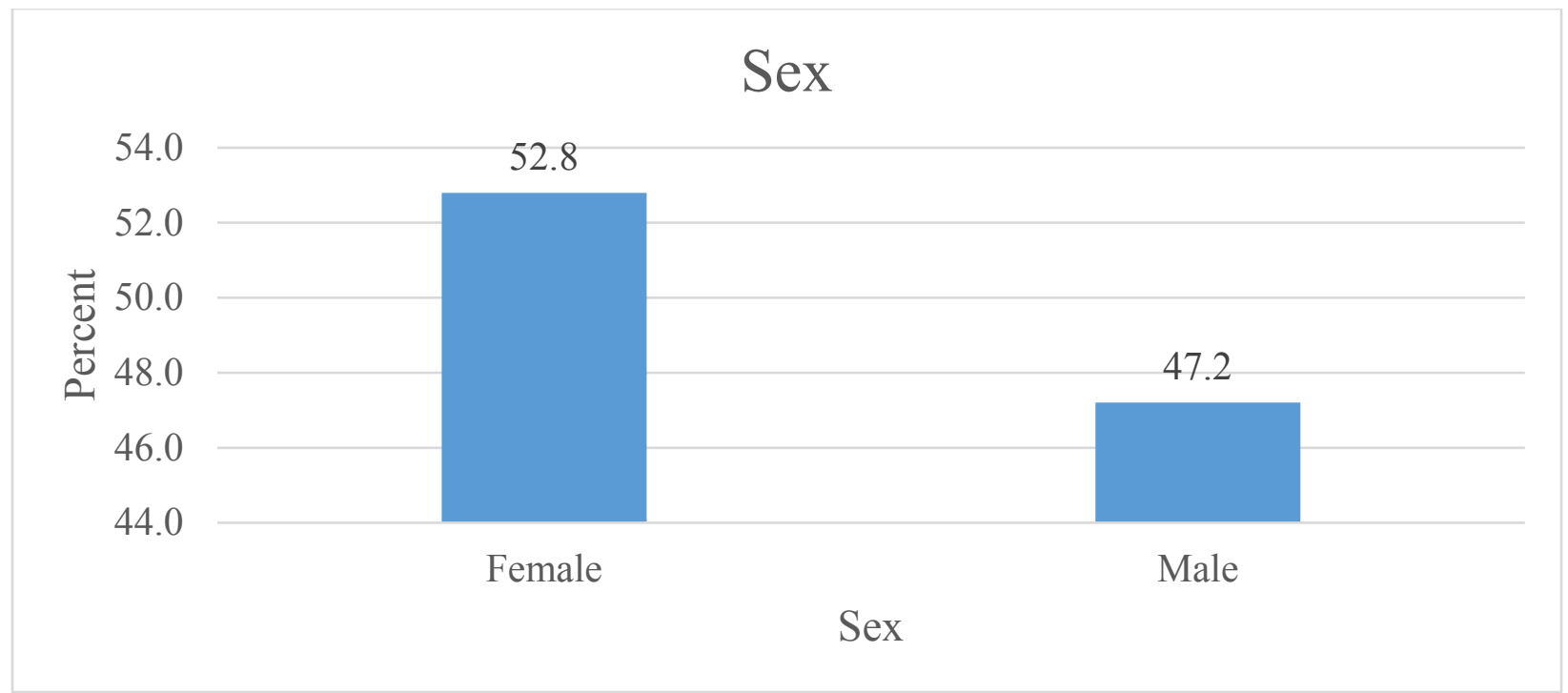

Figure 3. Sex in Percentages 
SOCIAL MEDIA USAGE

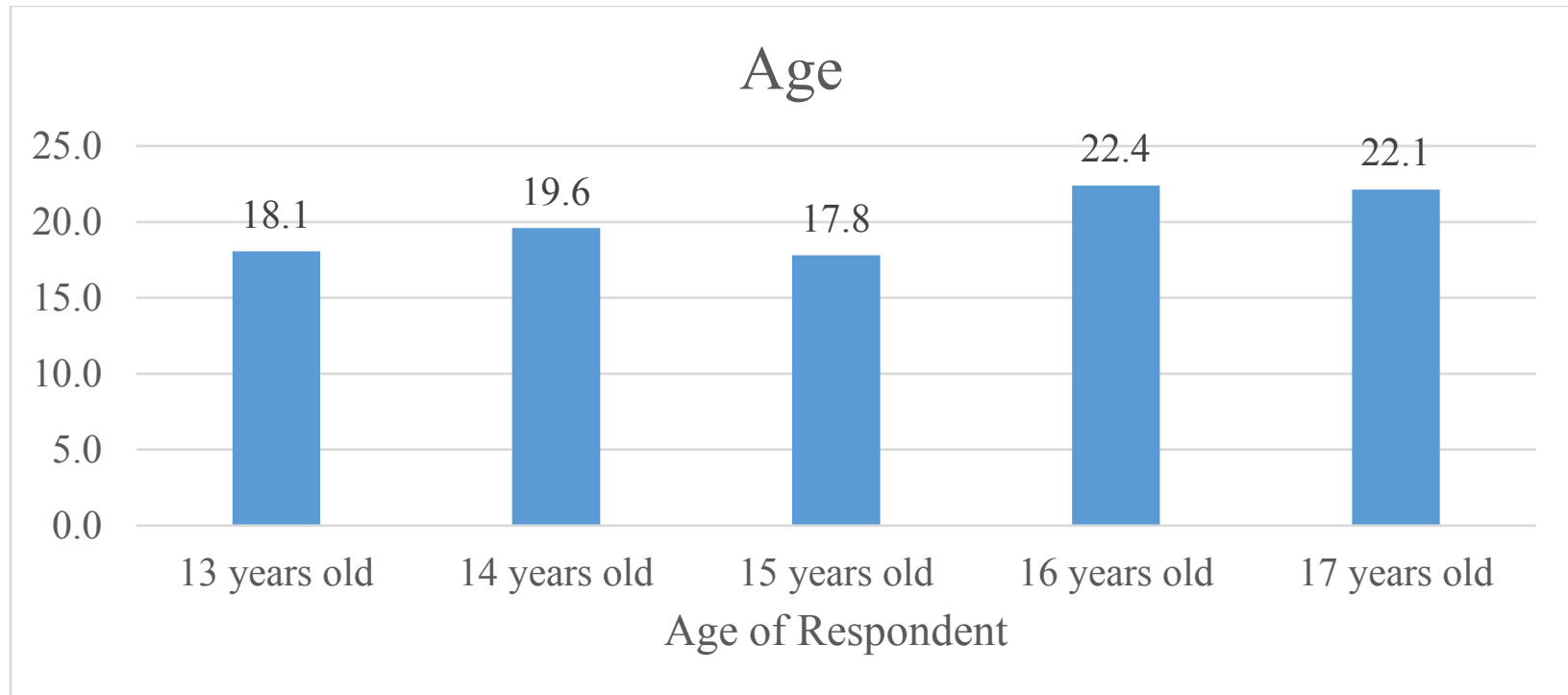

Figure 4. Age of Respondent in Percentages 